\title{
Planned End Date
}

National Cancer Institute

\section{Source}

National Cancer Institute. Planned End Date. NCI Thesaurus. Code C133397.

The calendar date that an event or activity is intended to be completed. 